\title{
Zinc finger protein 667 expression is upregulated by cerebral ischemic preconditioning and protects cells from oxidative stress
}

\author{
DUN YUAN, JUN HUANG, XIANRUI YUAN, JIE ZHAO and WEIXI JIANG
}

Department of Neurosurgery, Xiangya Hospital, Central South University, Changsha, Hunan 410008, P.R. China

Received March 13, 2013; Accepted May 25, 2013

DOI: 10.3892/br.2013.124

\begin{abstract}
Brain ischemic injury is associated with clinical emergencies such as acute ischemic and hemorrhagic stroke, head trauma, prolonged severe hypotension and cardiac arrest. Ischemic preconditioning (IPC) is the most powerful endogenous mechanism against ischemic injury. However, the majority of IPC treatments are invasive and thus impractical in the clinical setting. Identifying the endogenous neuroprotective mechanism induced by IPC is important for developing new strategies to reduce stroke severity. Zinc finger protein 667 (ZNF667) is a novel zinc finger protein that is upregulated by myocardial IPC. However, its functional role in neuronal ischemia has not been elucidated. In this study, the changes of ZNF667 expression on cerebral IPC and its potential neuroprotective function were investigated. The cerebral ischemia model was established by ameliorated four-vessel occlusion in rats. The northern blot results demonstrated that ZNF667 expression was increased in the hippocampus and cortex at 12 and $24 \mathrm{~h}$ after cerebral ischemic pretreatment. To investigate the neuroprotective function of ZNF667, enhanced green fluorescent protein (EGFP)-ZNF667 fusion protein was expressed in $\mathrm{C} 2 \mathrm{C} 12$ and brain astrocytoma cells and its subcellular localization was detected by confocal microscopy. EGFP-ZNF667 fusion proteins were localized in the nucleus of $\mathrm{C} 2 \mathrm{C} 12$ and brain astrocytoma cells, indicating that ZNF667 may act as a transcription factor in neural cells. To mimic oxidative stress associated with ischemia/reperfusion injury, hydrogen peroxide $\left(\mathrm{H}_{2} \mathrm{O}_{2}\right)$ was used to treat cells. Cell viability was measured by the lactate dehydrogenase (LDH) and WST-1 assays. A decrease in viability was detected in $\mathrm{C} 2 \mathrm{C} 12$ and astrocytoma cells following $\mathrm{H}_{2} \mathrm{O}_{2}$ treatment, whereas ZNF667 gene overexpression significantly improved cell viability following $\mathrm{H}_{2} \mathrm{O}_{2}$ treatment. These results suggested that ZNF667 plays a neuroprotective role by acting as a transcription factor in cerebral IPC.
\end{abstract}

Correspondence to: Dr Weixi Jiang, Department of Neurosurgery, Xiangya Hospital, Central South University, 87 Xiangya Road, Changsha, Hunan 410008, P.R. China

E-mail: weixijiang111@gmail.com

Key words: cerebral ischemic preconditioning, zinc finger protein 667 , gene expression, oxidative stress, cell protection

\section{Introduction}

Brain ischemic injury is associated with several clinical emergencies, including acute ischemic stroke, acute hemorrhagic stroke, head trauma, prolonged severe hypotension and cardiac arrest (1). Brief sublethal ischemia may protect the brain from subsequent sustained ischemic insults, a phenomenon known as ischemic preconditioning (IPC) $(2,3)$. Although the neuroprotective effects of IPC have been extensively approved, IPC has not been successfully applied in the clinical setting. Therefore, identification of the endogenous mechanisms induced by IPC is important for the development of pharmacological agents to treat ischemic brain injury. As an adaptive mechanism, IPC induces specific changes in gene expression patterns $(4,5)$. These changes evoke endogenous defense mechanisms. Zinc finger protein 667 (ZNF667) is a novel $\mathrm{C} 2 \mathrm{H} 2$ zinc finger protein that is upregulated in rat hearts during myocardial IPC $(6,7)$. It was demonstrated that ZNF667 binds to a consensus DNA sequence and represses the reporter gene expression, indicating that ZNF667 may function as a transcriptional repressor (8). To the best of our knowledge, there are no studies available on the ZNF667 expression pattern in brain IPC and the functional role of ZNF667 in IPC has not been elucidated. In the present study, ZNF667 expression was measured in the hippocampus and cortex at different time points after cerebral IPC treatment and it was found to be increased at 12 and $24 \mathrm{~h}$ after IPC treatment. To investigate the function of ZNF667, ZNF667 or ZNF667 fused with an enhanced green fluorescent protein (EGFP) tag was transfected into $\mathrm{C} 2 \mathrm{C} 12$ and brain astrocytoma cells. It was observed that the ZNF667-EGFP fusion protein became localized in the nucleus of $\mathrm{C} 2 \mathrm{C} 12$ and astrocytoma cells and ZNF667 overexpression protected these cells from hydrogen peroxide $\left(\mathrm{H}_{2} \mathrm{O}_{2}\right)$-induced damage. These results indicated that ZNF667 plays an important role in brain IPC by acting as a transcription factor to elicit a brain cytoprotective effect against ischemic damage.

\section{Materials and methods}

Plasmid construction. ZNF667 ORF was amplified from pGEM-T-ZNF667 vector (kindly provided by the Department of Pathophysiology, Xiangya School of Medicine, Central South University, Changsha, Hunan, China) using primer pairs with 5' XhoI or KpnI restriction sites (ZNF667-5'Xho1: 5'-atc 
tctcgagtaatgcctgcagcccgaggga-3'; ZNF667-3'Kpn1: 5'-atctgg taccgeggacatttcctcegaatgtatac-3'). ZNF667 ORF was then cloned into pcDNA3.1 or pEGFP-N1 vector at the XhoI and KpnI sites.

Rat cerebral IPC model. The rats were randomly divided into the IPC treatment and sham-operated control groups $(n=12$ per group). Each rat was fasted for $12 \mathrm{~h}$ prior to the operation, whereas access to water was allowed. Intraperitoneal injection of $30 \mathrm{mg} / \mathrm{kg}$ nembutal was used for anaesthesia. The cerebral ischemic pretreatment model was established by ameliorated four-vessel occlusion (9). IPC was induced by occlusion of the two common carotid arteries for $3 \mathrm{~min}$. The sham-control group rats were subjected to the same anesthesia and surgical procedure, without artery occlusion. The experimental protocols and animal handling procedures were performed in accordance with the National Institutes of Health guidelines for the use of experimental animals and approved by the Institutional Animal Care and Use Committee of the Central South University, China.

Northern blot analysis. RNA was extracted from the rat hippocampi and cortices at 2, 6, 12 and $24 \mathrm{~h}$ after brain IPC treatment, fractionated by agarose gel electrophoresis, transferred to a Hybond-N membrane (Amersham Biosciences Inc., Buckinghamshire, UK) and then hybridized with DNA probes labeled with P32-dCTP using the Amersham Rediprime $^{\mathrm{TM}}$ II random prime labeling system (GH Healthcare Inc., Buckinghamshire, UK). Hybridization was performed overnight at $58^{\circ} \mathrm{C}$ in Perfect $\mathrm{Hyb}^{\mathrm{TM}}$ Plus hybridization buffer (Sigma-Aldrich Co., St. Louis, MO, USA). The filters were washed at $58^{\circ} \mathrm{C}$ in $2 \mathrm{X} \mathrm{SSC}(0.15 \mathrm{M}$ sodium chloride/ $0.015 \mathrm{M}$ sodium citrate, $\mathrm{pH} 7.0$ ) with $0.1 \%$ SDS for $30 \mathrm{~min}$, followed by two washes in $0.2 \mathrm{X}$ SSC containing $0.1 \%$ SDS for $30 \mathrm{~min}$ per wash. Radioactive bands were detected by autoradiography.

Subcellular localization of ZNF667 in C2C12 and astrocytoma cells. pEGFP-ZNF667 was transfected into $\mathrm{C} 2 \mathrm{C} 12$ or astrocytoma cells by lipofectamine. EGFP fluorescence was detected by confocal microscopy $24 \mathrm{~h}$ after transfection.

Oxidative stress induced by $\mathrm{H}_{2} \mathrm{O}_{2}$. The pcDNA3.1 vector or pcDNA3.1-ZNF667 was transfected into $\mathrm{C} 2 \mathrm{C} 12$ or astrocytoma cells. The cells were incubated in DMEM-10\% fetal bovine serum (FBS) overnight. Cultures were subsequently washed 3 times with phosphate-buffered saline (PBS) and exposed to $0.5 \mathrm{~mm}$ hydrogen peroxide $\left(\mathrm{H}_{2} \mathrm{O}_{2}\right.$; Sigma-Aldrich Co. $)$ in serum-free DMEM for 3 or $24 \mathrm{~h}$ prior to the lactate dehydrogenase (LDH) release or WST-1 assays.

Cell damage detected by the $\mathrm{LDH}$ release assay. $\mathrm{LDH}$ is a stable cytoplasmic enzyme that is present in all cells. $\mathrm{LDH}$ is rapidly released into the cell culture supernatant upon cell damage or lysis. Therefore, it may be used to detect cell damage in in vitro cell culture systems. C2C12 or astrocytoma cells were transfected with the pcDNA3.1 or the pcDNA3.1-ZNF667 vector and incubated in DMEM-10\% FBS overnight. Cultures were subsequently washed 3 times with PBS and exposed to $0.5 \mathrm{~mm} \mathrm{H}_{2} \mathrm{O}_{2}$ in serum-free DMEM for $3 \mathrm{~h}$. The LDH activity was monitored with the LDH assay kit (Beijing Zhongsheng Bioreagent, Beijing, China), according to the manufacturer's instructions. Cytotoxicity (\%) was determined using the equation:

$\%$ cytotoxicity $=\left(\frac{\mathrm{LDH} \text { activity in cell culture medium }}{\mathrm{LDH} \text { activity in cell culture medium }+\mathrm{LDH} \text { activity in total cells }}\right) \times 100$

Cell viability detected by the WST-1 assay. The stable tetrazolium salt WST-1 is cleaved to a soluble formazan by a complex cell mechanism that occurs primarily on the cell surface. This bioreduction is largely dependent on the glycolytic production of $\mathrm{NAD}(\mathrm{P}) \mathrm{H}$ in viable cells. Therefore, the amount of formazan dye formed directly correlates with the number of metabolically active cells in the culture. The measured absorbance directly correlates with the number of viable cells. C2C12 or astrocytoma cells were transfected with the pcDNA3.1 or pcDNA3.1-ZNF667 vector. Cells were incubated in DMEM-10\% FBS overnight and then exposed to $0.5 \mathrm{mM} \mathrm{H}_{2} \mathrm{O}_{2}$ for $24 \mathrm{~h}$. Cell viability was assessed with the WST-1 assay kit (Roche Applied Science, Indianapolis, IN, USA). The cells were incubated with WST-1 reagent for $4 \mathrm{~h}$ at $37^{\circ} \mathrm{C}$ and $5 \% \mathrm{CO}_{2}$ and were then agitated thoroughly for $1 \mathrm{~min}$. The dye absorbance was measured at $425 \mathrm{~nm}$ with a reference wavelength of $690 \mathrm{~nm}$.

Statistical analysis. Data were presented as mean \pm standard error of the mean. ANOVA and the Student's t-test were used to determine statistical significance. A P-value of 0.05 was considered to indicate a statistically significant difference.

\section{Results}

ZFN667 is upregulated in the hippocampus and cortex at 12 and 24 following cerebral ischemic pretreatment. A total of 24 rats were subjected to IPC or sham operation $(n=12$ per group). In the IPC group, ameliorated four-vessel occlusion was applied for $3 \mathrm{~min}$. Rats were then allowed to recover for $2,6,12$ or $24 \mathrm{~h}$ prior to euthanasia. Hippocampal and cortical rat brain tissues were collected and RNA was extracted. The expression of the ZNF667 gene in the hippocampus and cortex of rat brains was detected by northern blot analysis. ZNF667 was upregulated in the hippocampus and cortex at 12 and $24 \mathrm{~h}$ after ischemic pretreatment in the IPC group, whereas no changes were observed in the sham operation group (Fig. 1).

ZNF667 is located in the nucleus of C2C12 and brain astrocytoma cells. ZNF667 has a Krüppel-associated box (KRAB) domain in the $\mathrm{N}$-terminus and 14 successive $\mathrm{C} 2 \mathrm{H} 2$ zinc finger domains in the middle and the $\mathrm{C}$-terminus, suggesting that it may function as a nuclear transcriptional factor. To determine its subcellular localization in neural cells, ZNF667 was fused with an EGFP tag and the construct was transfected into $\mathrm{C} 2 \mathrm{C} 12$ and brain astrocytoma cells. The $\mathrm{C} 2 \mathrm{C} 12$ mouse myoblast cell line was used for comparison with neural cells and the empty pEGFP-N1 vector was used as the negative control. EGFP fluorescence was observed under confocal microscopy $24 \mathrm{~h}$ after transfection. The pEGFP-ZNF667 fusion protein was localized exclusively in the nucleus of $\mathrm{C} 2 \mathrm{C} 12$ and astrocytoma cells (Fig. 2), indicating that ZNF667 is a nuclear protein. By contrast, the pEGFP-N1 control vector was homogenously 
A
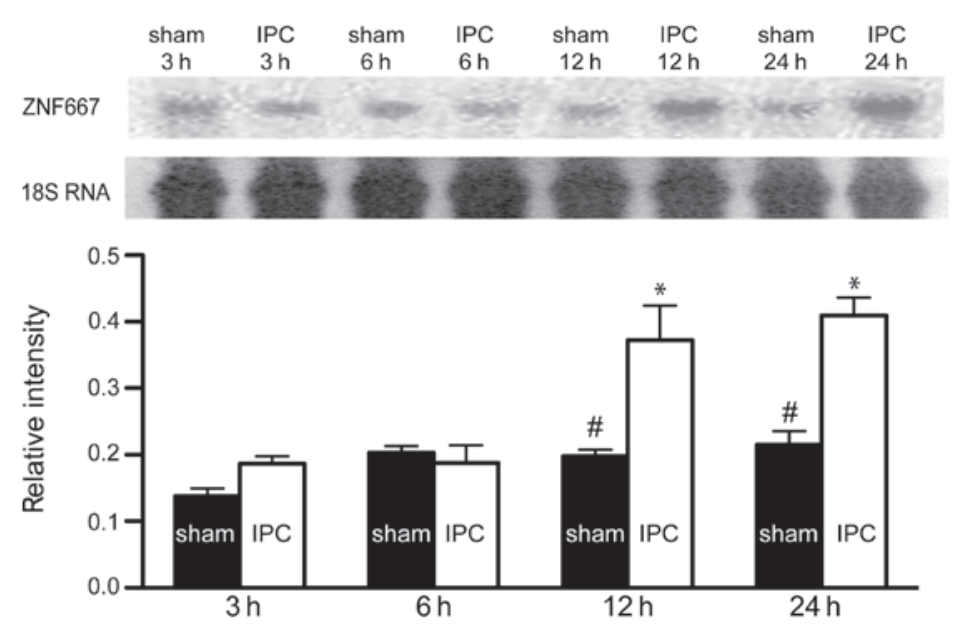

B
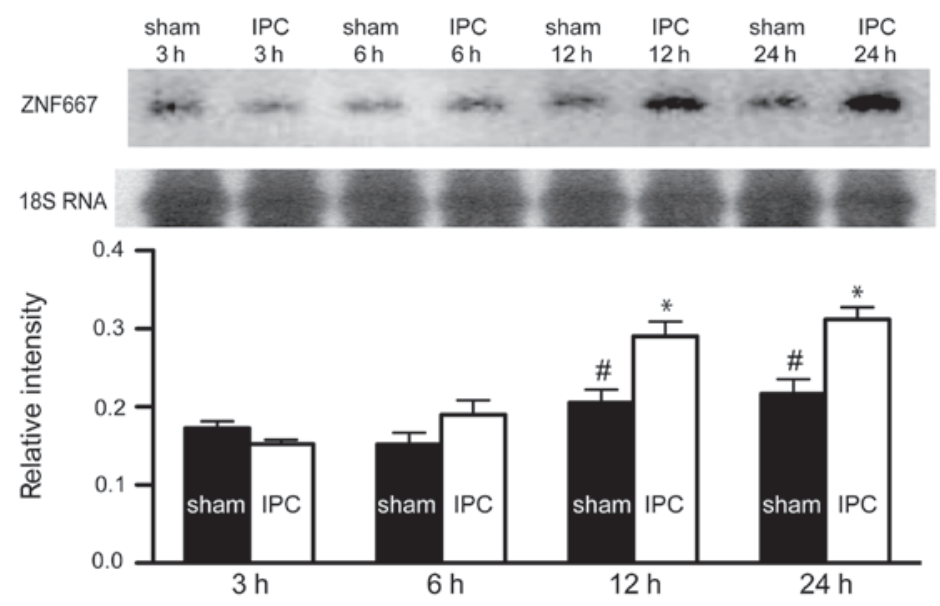

Figure 1. Cerebral ischemic pretreatment (IPC) upregulates zinc finger protein 667 (ZNF667) mRNA levels in rat brains. Northern blot analyses of ZNF667 mRNA expression levels in rat brain (A) hippocampus and (B) cortex at various time points following cerebral IPC. The band intensity of ZNF667 mRNA was normalized to that of 18S RNA bands. A significant increase in ZNF667 mRNA expression was oberved in the hippocampus and cortex 12 and $24 \mathrm{~h}$ after IPC treatment. ${ }^{*} \mathrm{P}<0.05$ vs. sham operation group (\#).

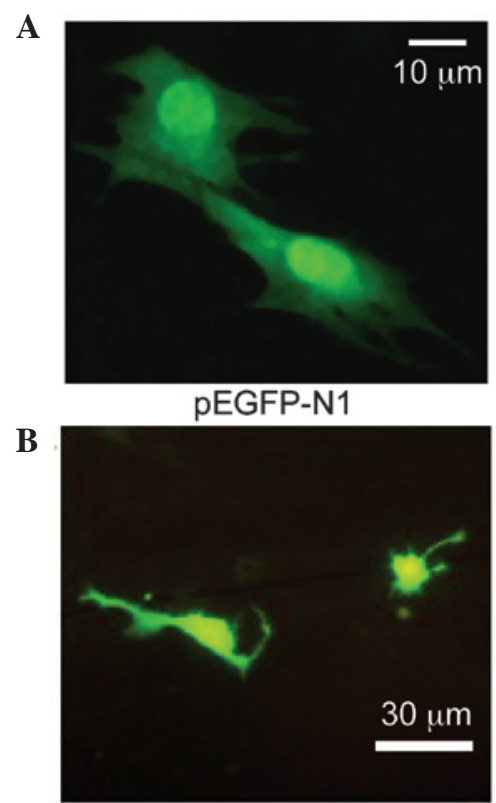

pEGFP-N1

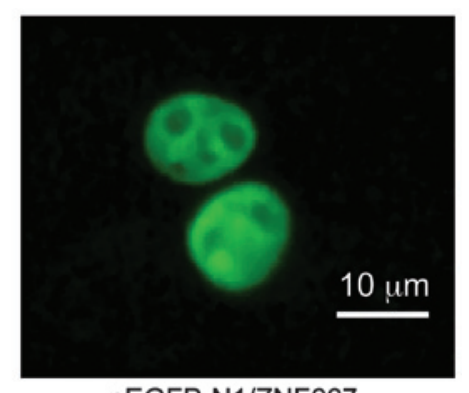

pEGFP-N1/ZNF667

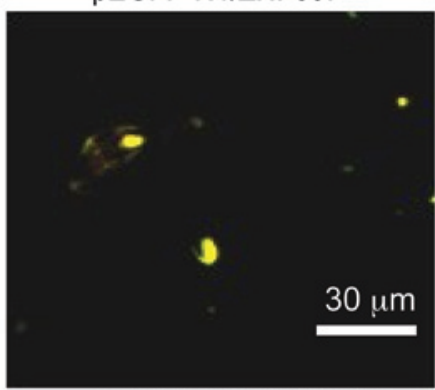

pEGFP-N1/ZNF667

Figure 2. Exogenously expressed zinc finger protein 667 (ZNF667) is localized in the nucleus of C2C12 and brain astrocytoma cells. Confocal microscopy images of (A) C2C12 cells and (B) brain astrocytoma cells transfected with pEGFP-N1 (control) and pEGFP-N1/ZNF667 constructs. Green fluorescent protein (GFP) fluorescence was observed under confocal microscopy after $24 \mathrm{~h}$ of transfection. Control enhanced GFP (EGFP) fluorescence was shown to be localized in the cytoplasm and nucleus, whereas EGFP-ZNF667 fusion protein was localized only in the nucleus. 
A

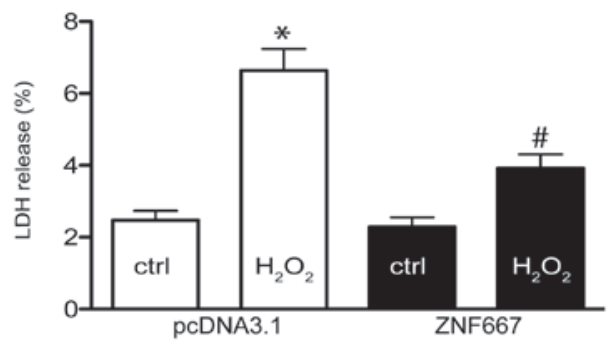

B

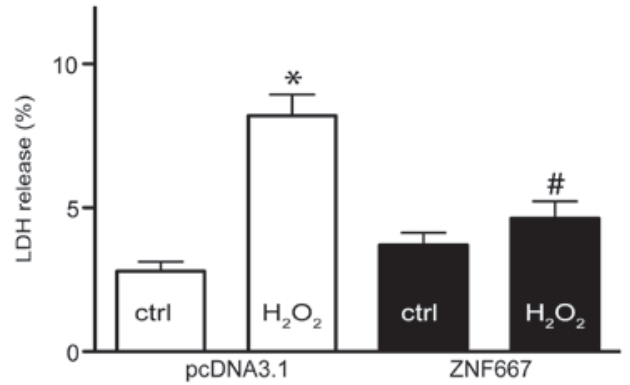

Figure 3. Overexpression of zinc finger protein 667 (ZNF667) reduces lactate dehydrogenase $(\mathrm{LDH})$ release from $\mathrm{C} 2 \mathrm{C} 12$ and brain astrocytoma cells induced by $\mathrm{H}_{2} \mathrm{O}_{2}$ treatment. (A) $\mathrm{C} 2 \mathrm{C} 12$ cells and (B) brain astrocytoma cells were transfected with pcDNA3.1 vector (pcDNA3.1) and pcDNA3/ZNF667 (ZNF667) constructs. Following transfection, cells were treated with $0.5 \mathrm{mmol} / 1 \mathrm{H}_{2} \mathrm{O}_{2}$ for $3 \mathrm{~h}$. After exposure of the cells to oxidative stress, cell damage was assessed by the $\mathrm{LDH}$ release assay. An increase of $\mathrm{LDH}$ release was detected in $\mathrm{C} 2 \mathrm{C} 12$ and astrocytoma control cells after $\mathrm{H}_{2} \mathrm{O}_{2}$ treatment, whereas ZNF667 gene overexpression significantly reduced $\mathrm{LDH}$ release induced by $\mathrm{H}_{2} \mathrm{O}_{2}\left({ }^{*} \mathrm{P}<0.01\right.$ vs. pcDNA3.1 control (ctrl), $\mathrm{n}=6$; ${ }^{\#} \mathrm{P}<0.01$ vs. pcDNA3.1 $\mathrm{H}_{2} \mathrm{O}_{2}, \mathrm{n}=6$ ).

distributed in the cytoplasm and nucleus. The combination of this result with ZNF667 gene characterization and previously reported results (8), suggests that ZNF667 acts as a transcriptional factor in neural cells.

Effect of ZNF667 gene overexpression on cell damage and cell viability induced by oxidative stress. ZNF667 gene has been shown to be upregulated following cerebral ischemic pretreatment. To investigate whether it plays a role in regulating cell survival, ZNF667-expressing vector was transfected into $\mathrm{C} 2 \mathrm{C} 12$ or brain astrocytoma cells. Twenty-four hours after transfection, the cells were exposed to $0.5 \mathrm{mM} \mathrm{H}_{2} \mathrm{O}_{2}$ to mimic oxidative stress associated with ischemia/reperfusion injury. Cell damage was assessed by the LDH release assay and cell viability was assessed by the WST-1 assay. Cell damage was found to be increased and cell viability decreased in $\mathrm{C} 2 \mathrm{C} 12$ and astrocytoma control cells following $\mathrm{H}_{2} \mathrm{O}_{2}$ treatment, whereas ZNF667 gene overexpression significantly decreased cell damage and improved cell viability after $\mathrm{H}_{2} \mathrm{O}_{2}$ treatment (Figs. 3 and 4). These data indicate that Mipu1 gene overexpression may protect cells from oxidative stress-induced injury.

\section{Discussion}

Ischemic brain injury is one of the leading causes of mortality and long-term disability worldwide (10). The physiological mechanisms of ischemic injury have not been fully elucidated and effective clinical therapies are not currently available. The most effective treatment is recovery of blood supply to the ischemic brain tissue; however, reperfusion itself may
A

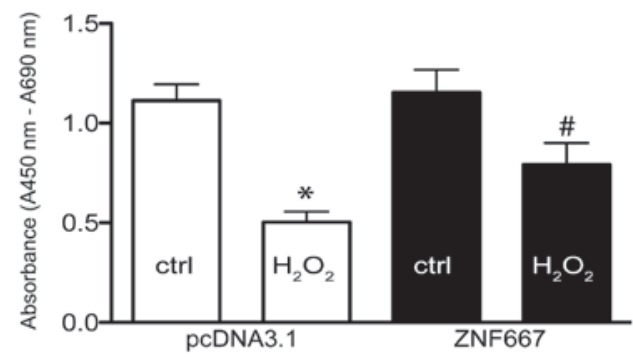

B

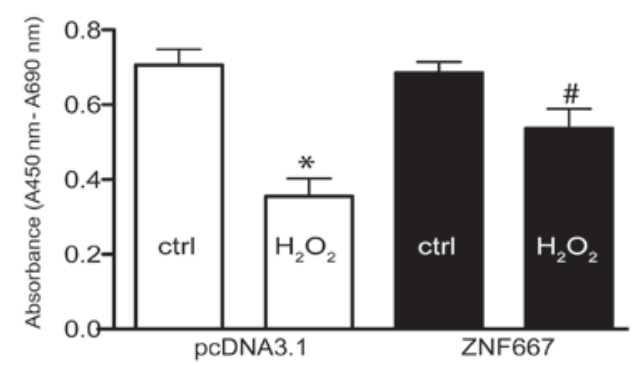

Figure 4. Overexpression of zinc finger protein 667 (ZNF667) increased the viability of $\mathrm{C} 2 \mathrm{C} 12$ and brain astrocytoma cells treated with $\mathrm{H}_{2} \mathrm{O}_{2}$. (A) $\mathrm{C} 2 \mathrm{C} 12$ cells and (B) brain astrocytoma cells transfected with pcDNA3.1 vector (pcDNA3.1) and pcDNA3/ZNF667 (ZNF667) were treated with $0.5 \mathrm{mmol} / 1$ $\mathrm{H}_{2} \mathrm{O}_{2}$ for $24 \mathrm{~h}$. Cell viability was then determined by the WST-1 assay. A decrease in cell viability was detected in $\mathrm{C} 2 \mathrm{C} 12$ and astrocytoma control cells after $\mathrm{H}_{2} \mathrm{O}_{2}$ treatment, whereas ZNF667 gene overexpression significantly increased cell viability after $\mathrm{H}_{2} \mathrm{O}_{2}$ treatment (" $\mathrm{P}<0.01$ vs. pcDNA3.1 control (ctrl), $\mathrm{n}=6$; ${ }^{\#} \mathrm{P}<0.01$ vs. pcDNA3.1 $\mathrm{H}_{2} \mathrm{O}_{2}, \mathrm{n}=6$ ).

cause cell damage due to the generation of reactive oxygen species $(11,12)$. IPC or ischemic tolerance has been shown to provide protection against neuronal death in brains submitted to subsequent periods of prolonged ischemia. Thus, neuroprotection associated with IPC shows therapeutic potential for brain ischemic injury. However, the underlying molecular mechanisms require further elucidation.

Gene microarray and proteomics analyses suggested that the induction of endogenous neuroprotective genes plays an important role in the acquisition of ischemic tolerance (13-15). $\mathrm{C} 2 \mathrm{H} 2$ zinc-finger proteins (ZFPs) constitute the largest family of transcription factors in higher eukaryotes (16-18). $\mathrm{C} 2 \mathrm{H} 2-\mathrm{ZFPs}$ were shown to be required for key cell processes, including transcriptional regulation, development, pathogen defense and stress responses. ZFPs were shown to be upregulated by IPC $(15,19)$, although the role of ZFPs in cerebral ischemia is controversial. For example, EGR-1, which is upregulated following focal and global ischemia, was shown to induce apoptotic cell death in certain studies $(20,21)$. However, other findings demonstrated that EGR-1 inhibits apoptosis following ultraviolet irradiation (22). In this study we observed that ZNF667 expression was increased in the hippocampus and cortex at 12 and $24 \mathrm{~h}$ after brain IPC treatment and the overexpression of ZNF667 protected $\mathrm{C} 2 \mathrm{C} 12$ and brain astrocytoma cells from oxidative stress-induced damage. These results suggest that ZNF667 may play a neuroprotective role in cerebral IPC.

ZNF667 protein has a KRAB domain in the N-terminus. Approximately one-third of $\mathrm{C} 2 \mathrm{H} 2-$ ZFPs exhibit KRAB motifs at their N-termini (23). The KRAB domain functions 
as a transcriptional repressor (24). Our results demonstrated that ZNF667 is localized in the nucleus of $\mathrm{C} 2 \mathrm{C} 12$ and brain astrocytoma cells, which is coincident with transcriptional factors. It was previously demonstrated that ZNF667 binds to a consensus DNA sequence and represses the reporter gene expression, indicating that ZNF667 may function as a transcriptional repressor (8). It was reported that preconditioning may downregulate genes that control metabolism, cell-cycle and ion channel activity (25). Similar adaptive neuroprotective mechanisms have been observed in hibernation and other hypoxia-tolerant states. Thus, as in hibernation, preconditioning may elicit endogenous genetic adaptations that confer tolerance to ischemic injury. ZNF667 may contribute to the gene downregulation process induced by IPC.

In summary, the present study demonstrated that ZNF667 is upregulated by cerebral IPC. ZNF667 may play a role in the neuroprotection induced by IPC by acting as a transcriptional repressor. The elucidation of ZNF667 function and underlying mechanisms may help develop novel therapeutic strategies for ischemic brain injury.

\section{Acknowledgements}

This study was supported by the Hunan Science and Technology Project (no. 2011FJ3004) of China.

\section{References}

1. Donnan GA, Fisher M, Macleod M and Davis SM: Stroke. Lancet 371: 1612-1623, 2008.

2. Zemke D, Smith JL, Reeves MJ and Majid A: Ischemia and ischemic tolerance in the brain: an overview. Neurotoxicology 25: 895-904, 2004

3. Bhuiyan MIH and Kim YJ: Mechanisms and prospects of ischemic tolerance induced by cerebral preconditioning. Int Neurourol J 14: 203-212, 2010.

4. Shin JA, Park EM, Choi JS, Seo SM, Kang JL, Lee KE and Cho S: Ischemic preconditioning-induced neuroprotection is associated with differential expression of IL-1beta and IL-1 receptor antagonist in the ischemic cortex. J Neuroimmunol 7: 14-19, 2009.

5. Stenzel-Poore MP, Stevens SL and Simon RP: Genomics of preconditioning. Stroke 35: 2683-2686, 2004.

6. Yuan C, Lv QL, Chen GW, Liu Y and Xiao XZ: Identification of genes up-regulated during ischemic preconditioning in rats. Prog Biochem Biophys 30: 390-394, 2003.

7. Yuan C, Zhang HL, Liu Y, Wang QP and Xiao XZ: Cloning and characterization of a new gene Mip1 upregulated during myocardial ishemia-reperfusion. Prog Biochem Biophys 31: 231-236, 2004

8. Jiang L, Tang DL, Wang KK, Zhang HL, Yuan C, Duan D and Xiao X: Functional analysis of a novel KRAB/C2H2 zinc finger protein Mipu1. Biochem Biophys Res Commun 356: 829-835, 2007.

9. Pulsinelli WA and Brierley JB: A new model of bilateral hemispheric ischemia in the unanesthetized rat. Stroke 10: 267-272, 1979.

10. Strong K, Mathers C and Bonita R: Preventing stroke: saving lives around the world. Lancet Neurol 6: 182-187, 2007.
11. Cuzzocrea S, Riley DP, Caputi AP and Salvemini D: Antioxidant therapy: a new pharmacological approach in shock, inflammation, and ischemia/reperfusion injury. Pharmacol Rev 53: 135-159, 2001.

12. Valko M, Leibfritz D, Moncol J, Cronin MT, Mazur M and Telser J: Free radicals and antioxidants in normal physiological functions and human disease. Int J Biochem Cell Biol 39: 44-84, 2007.

13. Barone FC: Endogenous brain protection: models, gene expression, and mechanisms. Methods Mol Med 104: 105-184, 2004.

14. Dhodda VK, Sailor KA, Bowen KK and Vemuganti R: Putative endogenous mediators of preconditioning-induced ischemic tolerance in rat brain identified by genomic and proteomic analysis. J Neurochem 89: 73-89, 2004.

15. Kawahara N, Wang Y, Mukasa A, Furuya K, Shimizu T, Hamakubo T, Aburatani H, Kodama T and Kirino T: Genomewide gene expression analysis for induced ischemic tolerance and delayed neuronal death following transient global ischemia in rats. J Cereb Blood Flow Metab 24: 212-223, 2004

16. Rubin GM, Yandell MD, Wortman JR, Gabor Miklos GL, Nelson CR, Hariharan IK, Fortini ME, Li PW, Apweiler R, Fleischmann W, Cherry JM, Henikoff S, Skupski MP, Misra S, Ashburner M, Birney E, Boguski MS, Brody T, Brokstein P, Celniker SE, Chervitz SA, Coates D, Cravchik A, Gabrielian A, Galle RF, Gelbart WM, George RA, Goldstein LS, Gong F, Guan P, Harris NL, Hay BA, Hoskins RA, Li J, Li Z, Hynes RO, Jones SJ, Kuehl PM, Lemaitre B, Littleton JT, Morrison DK, Mungall C, O'Farrell PH, Pickeral OK, Shue C, Vosshall LB, Zhang J, Zhao Q, Zheng XH and Lewis S: Comparative Genomics of the Eukaryotes. Science 287: 2204-2215, 2000.

17. Razin SV, Borunova VV, Maksimenko OG and Kantidze OL: Cys2His2 zinc finger protein family: classification, functions, and major members. Biochemistry (Mosc) 77: 217-226, 2012.

18. Klug A and Schwabe JW: Protein motifs 5. Zinc fingers FASEB J 9: 597-604, 1995.

19. McKee SC, Thompson CS, Sabourin LA and Hakim AM: Regulation of expression of early growth response transcription factors in rat primary cortical neurons by extracellular ATP. Brain Res 1088: 1-11, 2006.

20. Catania MV, Copani A, Calogero A, Ragonese GI, Condorelli DF and Nicoletti F: An enhanced expression of the immediate early gene, Egr-1, is associated with neuronal apoptosis in culture. Neuroscience 91: 1529-1538, 1999.

21. Li H, Kolluri SK, Gu J, Dawson MI, Cao X, Hobbs PD, Lin B, Chen G, Lu J, Lin F, Xie Z, Fontana JA, Reed JC and Zhang X: Cytochrome $c$ release and apoptosis induced by mitochondrial targeting of nuclear orphan receptor TR3. Science 289: $1159-1164,2000$

22. Huang RP, Fan Y, deBelle I, Ni Z, Matheny W and Adamson ED: Egr-1 inhibits apoptosis during the UV response: correlation of cell survival with Egr-1 phosphorylation. Cell Death Differ 5: 96-106, 1998.

23. Witzgall R, O'leary E, Leaf A, Onaldi D and Bonventre JV: The Kruppel-associated box-A (Krab-A) domain of zinc-finger proteins mediates transcriptional repression. Proc Natl Acad Sci USA 91: 4514-4518, 1994.

24. Urrutia R: KRAB-containing zinc-finger repressor proteins. Genome Biol 4: 231, 2003.

25. Stenzel-Poore MP, Stevens SL, Xiong Z, Lessov NS, Harrington CA, Mori M, Meller R, Rosenzweig HL, Tobar E, Shaw TE, Chu Xan and Simon RP: Effect of ischaemic preconditioning on genomic response to cerebral ischaemia: similarity to neuroprotective strategies in hibernation and hypoxia-tolerant states. Lancet 362: 1028-1037, 2001. 